Measuring the Value of Cataract Surgery

Irving Shapiro, M.D.

Phillips Eye Institute

Matthew D. Shapiro

University of Michigan and NBER

David W. Wilcox

U.S. Department of the Treasury

June 1998

Revised March 1999

This paper is prepared for the NBER-CRIW conference on health care prices. We are grateful to Praveen Kache and Laura Marburger for research assistance. Matthew Shapiro gratefully acknowledges the financial support of the National Institute on Aging through the Michigan Exploratory Center on the Demography of Aging and program project 2-P01 AG 10170. We gratefully acknowledge the very helpful discussions with and comments of Andrew Abel, Zvi Griliches, Richard Suzman, and participants in the NBER Summer Institute. The views expressed in this paper are not necessarily those of the U.S. Department of the Treasury.

Irving Shapiro is Medical Director, Phillips Eye Institute, Minneapolis, Minnesota, and Clinical Professor, Department of Ophthalmology, University of Minnesota; Matthew Shapiro is Professor, Department of Economics and Faculty Associate, Survey Research Center, University of Michigan, and Research Associate, NBER; Wilcox is Assistant Secretary for Economic Policy, U.S. Department of the Treasury. . 
Measuring the Value of Cataract Surgery

\begin{abstract}
The technique for extracting cataracts has changed substantially over the last 50 years. Incisions and suturing have dramatically improved. Intraocular lens implants have eliminated the need for cataract spectacles or contact lenses. The surgery is now done on an outpatient basis. Post-operative visual results have improved substantially. The changes in technique have led to a large increase in the rate of cataract extraction and in reduced thresholds of visual impairment of patients having cataract surgery.

This paper documents these trends and studies how they impact on price measurement. The improved techniques for cataract surgery also consume substantially reduced resources per operation. The paper shows how current procedures for price measurement substantially overstate the rate of price increase when they are applied to cataract surgery. It discusses how to adjust the price of cataract extraction for quality taking into account the durability of the benefits. It also emphasizes the importance of accounting for the changing timing of cataract extraction in the course of the disease when demand for surgery increases as outcomes improve and patient burden falls.
\end{abstract}

Irving Shapiro, M.D.

Phillips Eye Institute

Minneapolis MN 55404

Matthew D. Shapiro

Department of Economics

University of Michigan

Ann Arbor MI 48109

and NBER

David W. Wilcox

U.S. Department of the Treasury

Washington DC 20220 


\section{Health Care and the Cost of Living}

The standard analytic framework for constructing a cost of living index compares the change in expenditure between a base and reference period needed to deliver a fixed level of utility. ${ }^{1}$ This framework, which relies on a stable, well-defined function relating per period expenditure to prices and utility, has serious limitations for measuring how health-care expenditures affect the cost of living.

! Health expenditure on life-extending therapies not only can increase current-period utility, but have durable effects on utility. Durability per se is not special to health care. The purchase of a refrigerator or car also provides for a flow of utility into the future. This aspect of durability can be handled in a cost of living index by taking a service-flow approach. ${ }^{2}$ By making the number of periods of life endogenous, health care expenditures can cause interesting, and even perverse, implications for cost-of-living measurement. Specifically, a life-saving expenditure can substantially increase the annuity value of expenditure needed to maintain a fixed level of per-period utility over a longer lifetime. ${ }^{3,4}$ Traditional cost of living measurement, which takes a per-period rather than a lifetime perspective,

${ }^{1}$ See Pollak (1989) or Diewert (1987).

${ }^{2}$ For the U.S. CPI, housing purchases, but not purchases of other durables, are accounted for on a service-flow basis. Hence, while the data requirements and other conceptual problems for measuring health remain highly problematic, durability in itself is not a unique complication.

${ }^{3} \mathrm{We}$ are grateful to Zvi Griliches for emphasizing this point to us.

${ }^{4}$ Indeed, for a person with fixed life-time resources, this a life-extending intervention could lead to an impoverishment of non-health expenditures as fixed resources are more thinly spread to maintain consumption over a longer lifespan. The annuity features of Social Security and Medicare, however, provide some insurance against these consequences of health expenditure. 
does not account for this effect.

! Most health care expenditure is driven by adverse shocks to health. Again, standard cost-of-living analysis, which compares a stable utility function across time, does not account for this aspect of health expenditure. These shocks will have direct effects on the demand for health care expenditures. They will also have cross-effects on demand for other expenditures even after compensation for the wealth effects of the health shock.

! Many medical treatment decisions are binary, with little scope for varying either the quantity of treatment or its quality. Especially in the United States, only treatments at or close to the state of the art are offered. ${ }^{5}$ Hence, health expenditures appear to be lumpy and exogenous, especially given the importance of third-party payment. Consequently, health care is not easily modeled in the marginalist framework that underlies the theory of cost-of-living indexes.

These points about health care--their potential life-and-death nature, their state-contingency, and their exogeneity--might drive one to the conclusion that economic analysis of the choice to undertake treatment is inappropriate. In this paper, we argue, however, that economic decision making by patients is important for understanding the demand for certain medical procedures. Shocks to health need not require acute treatment. Many conditions are chronic and progressive. The patient may face a slow, variable, and unpredictable progression of the disease. In such cases, the timing and nature of the treatment might be highly uncertain and variable across patients. Moreover, over time as treatment regimes change, the medical intervention may take place at a different point in the course of the disease. Even if the medical

${ }^{5}$ The state of the art does diffuse slowly, so there may be variation by the setting where the health care is delivered, by region, and so on. Moreover, patients with different access to health care (owing to insurance coverage, locale, education, or income) may receive different treatment. Yet, for a particular patient, there is typically little economic trade-off in the choice of treatment. 
intervention once it is indicated is exogenously determined by the state of the art, with little or no scope for varying the quantity or quality of the intervention, the timing of the intervention may be highly endogenous.

Some medical procedures have declining costs over time, possibility in pecuniary terms, but especially when quality of outcomes and reduced morbidity are taken into account. This declining cost has important consequences for the demand for the procedure to the extent that it relaxes the medical criteria for receiving treatment. Heterogeneity in the course of the disease makes it important to distinguish between these two margins of adjustment. For some patients, relaxed criteria for receiving a medical intervention will effect the timing of treatment, with treatment being received earlier in the course of the disease as criteria become more relaxed; for others with less serious disease, or with disease that is slower to progress, they might never become candidates for a treatment under tighter criteria, but will receive it under relaxed criteria, perhaps quite early in the course of the disease.

The demand for the procedure will increase as the effective price falls and the equilibrium moves down the demand curve. The movement down the demand curve means that the marginal valuation of the procedure is lower. Hedonic regression or survey assessments of the quality of outcomes from medical procedures will reveal declining marginal benefit over time. It would be incorrect, however, to mechanically apply such results in a cost of living analysis. In particular, to the extent that patients receive the intervention earlier in the course of the disease, the main benefits of the procedure might come many periods after the procedure. While the benefits of having the new procedure might be quite small in the period the procedure is carried out, substantial benefit accrues in subsequent periods where the patient avoids suffering the progressively worsening symptoms and disability while waiting to become a candidate for the former procedure. A cost-of-living index that takes into account only the benefit in the period the procedure is carried out will have a potentially large upward bias.

This paper will present a case study of cataract surgery. Dramatic changes in the technology for cataract surgery make it an excellent illustration of the importance of accounting for the timing of 
procedure in the course of a disease. We will argue in the conclusion, however, that similar considerations apply to the treatment of various medical conditions.

The organization of the remainder of the paper is as follows. Section 2 outlines developments in the techniques of cataract surgery since mid-century. It then discusses how these improvements in technique have reduced the degree of visual impairment of patients receiving cataract surgery, thereby dramatically increasing the rate of surgery. Section 3 discusses how the benefits of surgery should be valued across time given the changing visual function at time of surgery. Section 4 discusses the resource and monetary costs of cataract surgery. It presents a cost index for cataract surgery and contrasts the results with the current Bureau of Labor Statistics procedures for measuring health cost. Section 5 makes recommendations for measuring prices in the health-care sector based on the findings about cataract surgery. Section 6 offers conclusions.

\section{Treatment of Cataract}

This part of this section gives the chronology of treatment for cataract since World War II. The second part describes how changes in the techniques for cataract surgery and for post-operative optical correction changed the criteria for cataract surgery over time. The third part describes how these improvements have led to relaxed criteria for extraction of cataracts and dramatically increased rates of cataract extraction.

\subsection{Techniques of Cataract Surgery: A Chronology}

The lens focuses light coming into the eye onto the retina. A cataract is a cloudy lens, which can impair vision. Cataracts are removed surgically. Up to the late 1970s, no other lens was inserted into the eye, so anyone whose cataracts had been removed required thick glasses or contact lenses to provide focus. In the late 1970s, however, surgeons in the United States started inserting an intraocular lens (IOL) as a 
replacement for the cloudy, natural lens. IOLs eliminate the need for thick glasses or contact lenses. They leave the patient with much better postoperative vision than they could have obtained with the cataract glasses and eliminated the need for inserting, removing, and caring for contact lenses.

There have been dramatic changes in the technique of cataract surgery--how the incision is made, how the cataract is extracted, and how the incision is closed. In the immediate post World War II period, extracapsular extraction was the standard technique. This technique did not necessarily remove all the cataract. In the early 1950 s, the technique switched to intracapsular extraction, where the entire cataract and its enclosing envelope (capsule) were removed by suction or freezing. Because these techniques required a large incision, standard postoperative care included hospitalization often as long as a week. Through the 1960s, techniques of extraction and suturing gradually improved. These improvements were facilitated by the routine use of an operating microscope. Hospital stays were reduced to a typical stay of three days.

The modern era of extracapsular extraction opened in the early 1970s. This technique was pioneered with phacoemulsification, a technique where the cataract was broken into tiny pieces and removed from the eye by controlled suction. The smaller incisions allowed by phacoemulsification made outpatient treatment increasingly prevalent. Yet, the typical extractions remained intracapsular. Improvements in sutures and suture technique, giving more secure wound closure, allowed hospital stays with intracapsular extraction to fall to a single night. At the end of the 1970 s, there was an increasing trend to the use of phacoemulsification with its smaller incision.

The 1980s saw an increased use of phacoemulsification because of its small incision, complete removal of the cataract, and the reduced postoperative complications allowed by leaving the posterior capsule intact. Leaving the posterior capsule intact reduced postoperative complications. ${ }^{6}$

By 1990, phacoemulsification was common for extraction of the cataract. Improvements in

${ }^{6}$ The YAG laser could treat a clouded posterior capsule without invasive surgery. 
techniques in the 1990s included further reduction in the size of the incision. Smaller incisions can be closed with fewer sutures, resulting in better and faster healing of the wound. IOLs were designed to fit through the small incision. Indeed, it is now possible to make incisions that heal without suturing.

With reduced or no time needed for suturing, the operation can be completed quickly, sometimes in less than ten minutes. This improvement in surgical technique has allowed for innovations in the delivery of anaesthesia. The standard technique has been to inject the anaesthetic agents beside the eye and behind it. With a fast and highly controlled operation, anaesthesia can now be in the form of topical drops on the eye and anaesthetic agent in the irrigating solutions within the eye.

New developments in IOLs are improving post-operative vision. Standard IOLs are focussed at a fixed distance. Multifocal lenses, which are recently becoming common, allow focus at several distances.

See Table 1 for a summary of the evolution of cataract treatment, and an estimate of the number of days in hospital each treatment required for a typical patient with no other complications. ${ }^{7}$ The outpatient surgery includes both surgery done in a hospital and surgery done in outpatient clinics, which tends to cost less.

\subsection{Interaction of Improvement in Surgical Techniques and the Threshold for Surgery}

Throughout the period being studied, the criteria for surgery has been based on the extent to which the cataract impairs activities of daily life, such as work, reading, driving, and leisure activities. There are objective tests of visual acuity (e.g. Snellen visual acuity ${ }^{8}$ ) which are indicative of whether a patient is a candidate for surgery, but there are no hard and fast rules for assessing whether a patient is a candidate for surgery based on these measurements alone. The physician must assess other underlying medical

\footnotetext{
${ }^{7}$ There has also been a drop in the number of post-operative office visits required for follow up of the surgery and the length of time patients are routinely followed after surgery. Moreover, currently follow up visits are included in the surgeon's fee, while previously they were billed separately.
}

${ }^{8}$ The Snellen index is the familiar 20/20 scale. 
conditions--both of the eye and generally. Moreover, patients with similar visual impairment and medical conditions might have differing demands for treatment depending on how much they rely on good vision for work and daily life.

\subsubsection{Refractive Correction of Operated Eye}

Whether a cataract is operated depends importantly on the visual acuity in the other eye. If the other eye has good vision, it is possible for a patient to function well using the vision principally from that eye. Hence, in the era when cataracts were relatively costly and burdensome for the patient, it was not uncommon to leave a cataract unoperated when the other eye provided acceptable function. How an operated eye would interact with the unoperated eye had significant implications on the decision to operate. Prior to the widespread adoption of intraocular lenses, either spectacles or contact lenses supplied the refraction in place of the extracted, natural lens. Spectacles had the drawback of magnifying the image in the operated eye. Consequently, an operated eye corrected with spectacles could not be used in conjunction with another eye with good vision. This fact often led to a delay of surgery until the better eye deteriorated-often because of a second cataract that would be subsequently operated.

A contact lens could be used as an alternative to spectacles. Contact lenses did not magnify the visual image nearly as much, so the operated eye could be used in conjunction with the other eye. Contact lenses had other drawbacks. In particular, they were relatively difficult to insert, remove, and maintain. Especially for the relatively elderly population of cataract patients, contact lenses were an unattractive or sometimes infeasible alternative to spectacles. (See Table 2 for a summary of characteristics of alterative refractive corrections.)

The advent of the IOL radically altered the post-operative refractive correction. A modern IOL, apart from its fixed focus, provides essentially the same vision as a natural lens. It solved the problem of 
magnification by spectacles without the cumbersomeness of contact lenses. ${ }^{9}$ Hence, the advent of the IOL made it reasonable to operate a cataract of a substantially broadened population of patients, particularly those who had good vision in the unoperated eye. This technical change made a substantial contribution to the growth in the incidence of cataract surgery discussed in Section 2.3.

\subsubsection{Recovery and Complication}

The advent of the IOL was not alone responsible for the reduced thresholds of visual impairment for cataract surgery. The changes in techniques discussed in Section 2.1 substantially reduced the cost of cataract surgery from the point of view of the patient by providing for much faster recovery and substantially reduced risk of complications.

Ambulation. Currently, cataract surgery is performed almost exclusively on an outpatient basis. The surgery itself takes less than half an hour; the whole process takes only several hours. The patient is immediately ambulatory. In contrast, early cataract extraction required a hospital stay of a week, with the patient in bed to assure healing of the wound. During the 1960s and 1970s, the length and arduousness of the hospital stay decreased as improved surgical techniques made for faster healing (see Table 1).

Complications. Rates of complication have also declined substantially over the years. In earlier years, infection and problems with the incision were significant risks. Glaucoma was also a possible complication. The improvements in the operation reduced these complications progressively. The transition to intraocular lens implantation was not without its own complications. As with any new

${ }^{9}$ The IOL currently costs between $\$ 100$ and $\$ 200$. Spectacles and especially contact lenses probably cost more, when fitting and replacement are taken into account. The insertion of the IOL is included in the surgeon's fee for the cataract. (See Drummond [1988] for a discussion of the relative costs of IOL and preIOL treatment in the United Kingdom.)

Even with an IOL, the patient commonly needs to wear normal spectacles or contact lenses to correct the other eye and for focusses other than provided by the IOL. The patient has the option of choosing an IOL that is in focus at reading or distance. What focus is chosen depends on the vision in the other eye and the preferences of the patient. Multifocal IOLs are now becoming available. These reduce or eliminate the need for spectacles over a range of distances. 
procedure, there is a learning curve. Moreover, the IOL implantation sometimes led to a clouding of the posterior capsule, which needed to be treated subsequently by laser.

\subsection{Changing Rates of and Thresholds for Cataract Surgery}

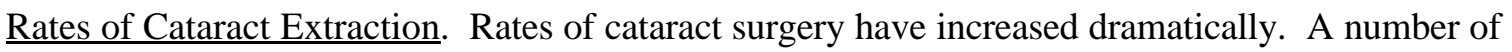
factors could account for the increase, such as improved access to care, higher rates of insurance coverage, improved general health among older patients, or increased incidence of the underlying disease. While we have not located studies that control for such factors, the consensus in the literature appears that the improvements in cataract surgery and reduced burden of surgery on the patient largely account for the increase in rates of surgery. For example, among residents of Olmsted County, Minnesota, where the population was presumably stable and insurance coverage for individuals over age 65 nearly universal, the rate of cataract extraction for individuals over 65 increased nearly by a factor of four from 1980 to 1994. As Figure 1 shows, most of the increase occurred in the 1980s, although the rate was still increasing in the 1990s [Baratz, et al. (1997)]. Other countries have also experienced substantial increases in rates of cataract extraction since approximately 1980. In earlier years, the rate of cataract surgery increased steadily, but at a much slower rate (Nadler and Schwartz \{1980]).

Pre-operative Visual Acuity. The time series of the distribution of visual acuity for patients having cataract operations confirms that cataracts are being extracted in patients with progressively better vision. ${ }^{10}$ Increased willingness to operate a cataract when the other eye is providing good vision indicates falling patient burden and improved results of the procedure.

Table 3 shows the visual acuity in the better eye (almost always the unoperated eye) for patients

\footnotetext{
${ }^{10}$ Visual acuity is far from a sufficient statistic for whether a patient is a good candidate for cataract surgery. Bass, et al. (1997) show that patients' desire to have surgery is more closely related to their survey responses about vision-related problems with daily life than to visual acuity. The differences in patients' function and preferences account for the heterogeneity in acuity before surgery.
} 
undergoing cataract surgery. Some care should be taken in comparing the results across location and across time. While the authors of the studies are aiming for consistency across time in the patient mix (e.g by excluding young patients or those with glaucoma, by sampling from the same practice over time), the controls in these retrospective studies are not perfect. More important, across location, there are substantial differences in design of the studies (the first eye of bilateral cataract in the first two Danish studies, monocular cataract in the second Danish study, a sample of all cataracts extracted in the U.S. study). Nonetheless, taking into account these fixed effects, a clear pattern emerges over time. In the years immediately after World War II, cataracts were seldom extracted when the better eye had good visual acuity (15 percent of cataract patients in Copenhagen in 1947-50 had acuity better than 20/60 in the better eye). Thirty percent of these patients were legally blind in the better eye (20/200 or worse). By 19691970, while it was still uncommon to operate when the better eye had good acuity, acuity in the better eye was substantially less likely to suffer extreme impairment. In 1947-50, acuity is uniformly distributed within the middle range. By 1969-70, it is skewed toward the better acuities. From 1970 to 1980 (Aarhus), there was only a slight improvement. This study does, however, document an increased tendency to operate the second eye during this period.

A dramatic change occurred during the transition from modern extracapsular extraction to intracapsular extraction with IOL implant. This transition is documented in the 1980/1992 data from Aarhus and the 1974/1982/1988 data for Baltimore. At the beginning of these periods, modern extracapsular extraction was almost universal. By the end, intracapsular extraction with IOL was almost universal. In Aarhus, the transition to IOLs led to an increase from one-quarter to one-half the fraction of cataract patients with acuity of better than $20 / 60$ in the better eye. The increase in Baltimore was smaller owing to the more aggressive treatment there at the beginning of the period. Nonetheless, for both the hospital-based and community-based practices in Baltimore, there is a substantial shift toward better acuity in the better eye for first cataract surgery. There is also a pronounced increase in the acuity of the better 
eye for second cataract surgery, especially in the hospital-based practice, after the transition to IOLs. ${ }^{11}$

Table 4 shows how the transition to IOL also led to better acuity in the operated eye at the time of cataract extraction. Cataracts are now typically extracted well before patients meet the threshold of legal blindness and occasionally in eyes with quite good acuity. Also, the IOL period brought a lengthening of the interval between first and second cataract extractions, which indicates that the first cataract is being operated earlier in the course of the disease [Moorman, et al. (1990), p. 765].

Age. Cataract is primarily a disease of older individuals. Moreover, some, but not all of cataracts are slowly progressive. Hence, reduced thresholds for treatment might lead to the average age of those getting cataract to fall over time. Other factors work in the opposite direction. Lengthening lifespans and improved health of the elderly increases the number of candidates for the operation. Moreover, the reduced burden of the operation on the patient makes it possible for a larger group of patients to receive it. Looking across studies, the average age of patients appears to be increasing. ${ }^{12}$

\section{Valuing Cataract Extraction over Time}

How does one value having a cataract extracted? The good is not the operation per se, but an improvement in vision. There is a literature on methods for valuing the improvement in vision from having a cataract extracted. ${ }^{13}$ This literature takes a lifetime perspective in evaluating the benefits of the procedure. Hence, it accounts for the durability of the operation, which is critical for appropriately

\footnotetext{
${ }^{11}$ In 1974, the fellow eye of the second operated eye would not have an IOL. In 1982, about half had IOLs. By 1988, almost all did.

${ }^{12}$ In Nørregaard, Pernth-Petersen, and Andersen (1996), it increased from 72.7 to 73.2 years from 1980 to 1992. It also increased in Moorman, et al. (1990) Miglior, et al. (1992) report average age of cataract patients at a clinic in Milan, Italy, increased from 67.5 years in 1956 to 71.5 years in 1987. Again, changes in mix of patients and the fact that in the case of the Baltimore study they are drawn from the potentially aging practices of particular physicians makes interpretation difficult.
}

${ }^{13}$ See Drummond (1990) and especially Ferguson, Buxton, and Drummond (1990) for an overview of different methods. 
accounting for the procedure in a cost of living index. The literature, like almost all the medical literature, does not compare the value of procedures over time. The medical literature is typically forward-looking. It asks, should a new procedure replace a current procedure, or is a procedure worth doing at all? It is typically not concerned with how today's standard of care compares with the standard of care from years ago. Yet, this comparison is what is required for construction of price and cost of living indexes. It is possible to string together a series of valuations of the standard of care at different points in time to construct a time-series of valuations. ${ }^{14}$ The message of the last section is, however, that changes in the standard of care change the mix of patients receiving the care. A contribution of this paper is to provide a framework for taking into account how the mix of patients varies endogenously with the changes in the cost of the procedure.

\subsection{Equilibrium Decision to Be Operated for Different Patients Under Different Treatment Regimes}

Figure 2 gives a stylized presentation of how changing criteria for surgery affects the timing of and benefit from getting a treatment. For each of the panels, the medical condition is shown on the vertical axis. In the case of cataract, this is visual function. As discussed above, visual function is related to, but not identical to, visual acuity. The vertical axis should be thought of as a scale that physician and patient use to determine whether or not to extract a cataract. Perfect vision is at the top of the scale; blindness is at the bottom. The horizontal axis is age. Tracking the disease as the patient ages has two purposes. First, it makes concrete the durable benefit of the procedure. (Drummond [1988] has a similar diagram.) Second, it shows how the timing of the operation changes for different progressions of the disease when the criterion for surgery changes.

The solid line in Figure 2 shows the progression of the disease in terms of visual function. The first column of figures shows the progression for a sudden onset of a severely debilitating cataract. The

\footnotetext{
${ }^{14}$ For procedures far back in time, the valuations would need to be done retrospectively.
} 
second column of figures shows a pattern of gradually worsening. Vision deteriorates slowly, perhaps over a period of several years. The third column shows the sudden onset of a mild disease. ${ }^{15}$ The dashed horizonal line shows the criterion for surgery. When visual function intersects this line, the operation is carried out. In the top row of figures, the criterion is at a low level of visual function, for example, corresponding to the relatively low levels of visual acuity for the typical cataract surgery patient in the preIOL era. In the bottom row, the threshold for surgery is at a substantially better level of visual function, corresponding to current practice. ${ }^{16}$

The dotted line at the top of the figures is the post-operative visual function. In the bottom row, it is somewhat higher than in the top row, reflecting the better post-operative results in the regime with relaxed surgical thresholds (i.e. IOLs give better results than spectacles or contact lenses). How it stands in relationship to the pre-onset function is an empirical matter. Figure 2 is drawn under the assumption that in the strict regime, the function does not recover to the pre-onset level. In the relaxed regime, visual function is actually better after the procedure than before the onset. This parameterization reflects the possibility that IOLs provide better refractive correction than did the patients' spectacles immediately before the onset of cataracts.

The shaded area is the benefit of having the operation, that is, the difference between the postoperative function and the function without the operation. Care should be taken in interpreting these figures. The criterion is not independent of the post-operative outcome. It is an equilibrium outcome based on a calculation that weighs the benefits of the operation cumulated over time--reflected in the shaded area-against the costs. These costs include the monetary cost discussed in the next section and the patient

\footnotetext{
${ }^{15}$ Many other courses of the disease are possible. There are different rates of progression, different timings of onset, and different levels of severity. The patterns shown in Figure 2 are, however, sufficiently general to capture the main interactions of criteria for treatment and the course of the disease.

${ }^{16}$ Visual function depends on both eyes. Thus, the thresholds shown in Figure 2 do reflect how changes in technique changed the role of vision in the unoperated eye in determining whether to do cataract surgery. A more complete analysis would, however, treat first and second cataract surgeries separately.
} 
burden in terms of recovery and complications discussed above. For many procedures, the relaxation of the threshold will be mainly determined by the improved outcome. In others, the post-procedure outcome is identical; the only change in criterion arises from reduced cost and patient burden. ${ }^{17}$ In cataract, the improved outcome plays an important role, but the reduced cost is also an important factor. Nonetheless, even though the intersection of the solid line and the dashed line represent an equilibrium outcome, not a decision rule, the shaded area in Figure 2 does represent the equilibrium benefit of having the procedure.

With sudden onset of severe disease, the patient gets the operation under either the strict or relaxed surgical procedure. The patient benefits from the improved outcome in the regime depicted in the lower row of Figure 2. With mild disease (last column of Figure 2), there is a dramatic difference in the treatment of disease. Under the criterion appropriate for the treatment regime depicted in the top row, the patient does not get the operation even though post-operative visual function would be improved. These benefits do not outweigh the cost, which may be monetary or in the form of burden on the patient of the operation (pain, recovery period, risk of complications). Under the regime depicted in the bottom of Figure 2, this same patient with mild disease would get the operation, getting substantial gain in visual function.

The middle column of Figure 2 depicts a patient with progressive disease. With the strict criterion, the operation is delayed. During this period, the patient suffers progressively worsening disease, but not serious enough disability to get the operation. Under the relaxed criteria, the patient gets the operation earlier, avoiding the potentially long period of worsening function while he or she would have been waiting to become a candidate under the former regime. Expectations about the course of the disease will be important in determining when the operation occurs. Early on, the patient with the progressive disease might not be distinguishable from the patient with mild disease. Since the course of cataract is difficult to predict, under the regime depicted in the top row, the operation would have been delayed. Under the second

\footnotetext{
${ }^{17}$ Chernew, Fendrick, and Hirth (1997) suggest that the increase in removal of gall bladder with the advent of much less invasive surgical techniques falls into this category.
} 
regime, both the mild and progressive cases would be operated relatively early. The benefit of the procedure to the patient who would have been progressive is much greater, though these patient will not be easy to distinguish ex post. Yet, it would be a serious mistake to value the procedure the same for them.

\subsection{Valuing the Benefits of the Operation}

To construct a price or cost-of-living index, the benefits depicted in Figure 2 need to be translated into units of value. In doing so, there are both conceptual difficulties and difficulties with lack of information. Two issues need to addressed: What is the metric for translating benefit into value? What is the population distribution of the course of disease?

\subsubsection{Metric for Valuing Benefits}

There is substantial literature on assessing the visual outcomes of cataract surgery. It is difficult to compare the studies across time because they typically report differing and somewhat vague subjective responses to questions about visual function (ability to read newspapers, ability to drive, etc). With some effort, an expert probably could, however, translate these survey responses into a standardized index of visual function. More recent studies use standardized survey instruments which yield standard indexes of visual function, which will facilitate comparison across time and locale (Steinberg, et al. [1994]).

One leading approach to assessing benefits of a medical procedure is the increment to qualityadjusted life-years (QALYs). Drummond (1988) uses Torrance, Boyle, and Horwood's (1982) utilitybased model of health states to assign a QALY to blindness and then discussed how that would be capitalized to take into account the multi-year benefit of cataract surgery. He also discusses a QALY calculation concerning the relative value of contact lenses versus IOLs for refractive correction after cataract surgery. The aim of this literature is to compare the cost-effectiveness of different treatments at a point in time (e.g. cataract extract versus hip replacement) rather than comparing the standard of care for a 
single disease over time. Yet, it could be adapted to that purpose. ${ }^{18}$

To use QALYs as units in a cost of living index, they need to be translated into units of value. An approach to doing so would be to measure willingness to pay. Studies assessing the willingness to pay for a QALY could be used to convert the disease-specific assessment of QALYs into monetary values.

Alternatively, the use of the QALY could be dispensed with if direct measures of willingness to pay were available. Such measures of willingness to pay could be obtained either by survey techniques or by observing patient choices when paying for the surgery is required, or an option to get faster or better care. ${ }^{19}$ Anderson, et al. (1997) report the result of a survey of patients waiting for cataract surgery at public clinics in Barcelona, Denmark, and Manitoba. They find that between 1/6 to 1/4 of patients who expected to wait over 7 months for the operation were willing to pay an amount averaging $\$ 1000$ (roughly the actual cost of getting the operation privately) to get it immediately. Smaller, but nonzero, factions were willing to pay to eliminate shorter waiting times. ${ }^{20}$ Willingness to pay increased with severity of the visual deficit and decreased with the amount to be paid.

Anderson, et al. also presents some confounding evidence on actual willingness to pay. In all three locales, private clinics are available as an alternative to the public clinics. Only 2 percent of the survey respondents switched to private clinics after being put on the waiting list at the public clinic. Yet, a substantial fraction of cataracts are done at these clinics (40 percent in Barcelona, 15 percent in Denmark, and not known in Manitoba). ${ }^{21}$ Hence, a sizeable fraction of the population is willing to bear a substantial

\footnotetext{
${ }^{18}$ For further discussion, see Shapiro, Shapiro, and Wilcox (1999).

${ }^{19}$ Such behavioral estimates would need to be done with great care owing to selection on income and seriousness of disease.

${ }^{20}$ For Barcelona, willingness-to-pay decreased with waiting time.

${ }^{21} \mathrm{~A}$ serious limitation of the study is that it excludes patients who were treated initially at private clinics, that is, who never entered the public system. Private patients were paying to avoid getting on waiting lists and for potentially better care.
} 
cost to gain a relatively short period of incremental benefit. This valuation could be used to value a perperiod slice of the benefits depicted in Figure 2. The Anderson, et al. survey also has the advantage of containing information about visual function, so the differing incremental benefits could be quantified.

\subsubsection{Assessing the Heterogeneity of the Course of Disease}

Figure 2 presents paths of visual function for different types of patients. While the paths are typical of the various possibilities of the course of development of a cataract, they are highly stylized. There is little empirical basis for quantifying these paths precisely, or establishing the distribution of courses of disease in the population. There are several problems with the base of knowledge. First, the medical literature tends to report visual function immediately before the operation. To distinguish among cases of sudden and progressive onset, it would be necessary to know visual function for several periods-possibly spanning years--before the operation. We know of no such study, although it could be done retrospectively by studying patient charts. Second, as noted above, the data on visual function is truncated at the point of the operation. Moreover, the point of truncation has varied endogenously over time.

Therefore, even were the problem of valuing benefits solved, there is not enough information now in hand to calculate the population distribution of the benefits at different points in time.

\section{4. $\quad$ A Prototypical Cost Index for Cataract Surgery}

The previous sections discuss how the techniques of cataract surgery have changed and how the reduced cost (mainly in terms of patient burden) and improved outcomes have increased the demand for the procedure. In this section, we focus on the monetary cost of cataract extraction. We do so by comparing the procedure the BLS would use in the CPI to price a cataract with an alternative procedure that more 
accurately reflects the actual cost. ${ }^{22}$ Our cost index--like the CPI--is based on the cost of inputs. In Section 5, we discuss an alternative methodology based on unit values for delivering care. Moreover, the calculations in this section do not reflect any adjustment for the quality of the outcome or the value of having the procedure earlier. We return to that issue in Section 5.

The CPI does not price treatment for cataracts per se, but instead prices hospital services and physician services, among other items. The BLS constructs an index of medical prices by first determining the relative importance weights in the base period (currently 1982-84) of the various inputs it is going to track, and then applying these weights to price indexes for the individual inputs. The BLS will reweight the basket of medical inputs in 1998 according to expenditure shares in 1993-95, and will then compute changes in the index from 1998 forward as weighted averages of the changes in the prices of the inputs.

This approach has a startling implication: Technological change that increases the efficiency of inputs in producing a good or service affects only the rate of change of the index of medical prices, but not in the first instance the level of the index. Indeed, the rate of change is only affected to the extent that the component price indexes grow at different rates. In the case of a procedure like cataracts, which has undergone revolutionary technological change, the change in the composition of the market basket (reflecting the sharp decline in the average length of hospital stay) will only be relevant for the subsequent growth of the index; the decline in the quantity of hospital services consumed will never be reflected in the level of the index.

To illustrate this problem, we have constructed a hypothetical CPI for cataracts. Our hypothetical CPI for cataract treatment is based on the information in Table 1, and the CPI components for physician and hospital services. We construct the hypothetical index by first estimating relative importance weights in hypothetical benchmark years for the physician services and hospital services required to treat a standard

\footnotetext{
${ }^{22}$ This section gives a more detailed discussion and update of the procedure introduced in Shapiro and Wilcox (1996).
} 
cataract patient. We then use these relative importance weights to aggregate the CPI components for physician and hospital prices. Specifically, we assume the quantities of services supplied are as in Table 5. The units of Table 5 are normalized to equal one night in the hospital. Somewhat arbitrarily, but not totally unrealistically, we have set the surgeon fee equal to the cost of one night in the hospital in the middle of the time period. There is no attempt to account for the cost of the refractive correction (spectacle or contacts in the early periods, IOLs in the later periods). ${ }^{23}$ The first column repeats the information on hospital nights from Table 1. In 1979, we assume that half the patients are treated in hospital and that half are treated on an outpatient basis. We calibrate the cost of the operating room in a hospital to equal the charge for four inpatient nights. For outpatient surgery, we calibrate it to equal 1.5 nights. In 1998, we reduce this to 1.3 owing to reduced costs of anaesthesia. The fourth column of Table 5 is thus the amount of hospital or outpatient clinic resources consumed by a cataract operation. It falls dramatically owing to the decline in inpatient nights and the lower cost of outpatient surgery. The surgeon time remained relatively constant through the earlier period. With the improvements in technique in the IOL period, it has fallen. Currently, cataracts can be extracted with substantially less time than at the end of the modern extracapsular regime in the mid-1970s owing mainly to changes in techniques for incisions and suturing. ${ }^{24}$

Table 6 shows the expenditure weights calculated by scaling the quantities in Table 5 by the level of the CPI components for hospital (CPI series SE56) and physician (CPI series SE5701) and calculating expenditure shares. ${ }^{25}$ The CPI component for hospital grew somewhat faster than that for physicians (see Table 7), so the decrease in the quantity of hospital is somewhat offset by the increase in price in calculating its share. At the beginning of the period, about one-fifth of the expenditure was on the surgeon.

\footnotetext{
${ }^{23}$ The table also subsumes the cost of the anesthesiologist into the hospital charge. It is often billed separately.

${ }^{24}$ Also, with faster healing, follow up office visits have been reduced substantially.

${ }^{25}$ In this version of the paper, the calculations in Tables 6 and 7 end with data in 1994.
} 
The share increased to about one-third in 1985, when it began to decline.

To calculate the hypothetical CPI, we weight the increases in the component indexes by the shares in hypothetical benchmark years of 1969 and 1979. As noted above, this procedure--which mimics that of the official CPI--never accounts for the fall in the level of hospital services. The level of the hypothetical CPI is shown as the solid bar in Figure 3; its growth rate is shown in the second column of Table 7. In contrast, we construct a prototypical unit value index by taking ratios of total expenditure, that is,

$$
\frac{\sum_{i} q_{i t} p_{i t}}{\sum_{i} q_{i b} p_{i b}} \text {, where } q_{i t} \text { is the quantity of component } i \text { at time } t \text { (Table 5), } p_{i t} \text { is the corresponding CPI }
$$

component, and $\mathrm{b}$ is the base year. In contrast to the CPI, this index does take into account the change in the level of the services. It does inherit any problems with the CPI component price indexes. For example, the CPI for physician services might not fully account for the discounts of actual from posted fees, which have increased substantially for cataract. On the other hand, surgeons' fees for cataract extraction have not declined in correspondence to the decline in inputs given in the last column of Table 5. Hence, the CPI for physician services times the input quantity may be biased up or down as an estimate of the per operation expenditure for surgeon's services.

The level of prototypical cost index is shown as the shaded bar in Figure 3; the growth rate is shown in the first column of Table 7. The prototypical index taking into account the decline in the level of inputs grows dramatically slower than the hypothetical CPI. For the 1969 to 1994 period as a whole, the hypothetical CPI grew 9.2 percent per year, or 3.5 percent per year relative to the total CPI. The prototypical index grew 4.1 percent per year. It actually fell relative to the total CPI over the whole period, and for all but one of the subperiods.

Hence, even without taking quality improvement into account, the prototypical index shows that 
the cost of cataracts fell relative to the published general price level. ${ }^{26}$ Admittedly, we selected cataract as an example because we knew it had dramatic changes that the CPI would miss. Nonetheless, it has features that are widely shared with other medical procedures, and indeed other goods.

\section{5. $\quad$ Lessons for Constructing Cost of Living Indexes}

This section outlines specific recommendations for constructing price indexes for health care based on what we have learned about the cost and value of cataract surgery in the proceeding sections. It will fall short of offering a quality-adjusted price index owing to the data limitations discussed in Section 3.

\subsection{Measure Cost with Unit Values for Treating a Medical Condition}

\subsubsection{Recommendation on Unit Values}

We recommend that unit values for treating a medical condition be used to measure the cost of health care. This recommendation has two components. First, the good should be defined as relief of a specific medical condition, not the receipt of a specific set of inputs. In the case of cataract, the good is the restoration of visual function following the clouding of the lens of the eye. Second, instead of pricing a basket of inputs, the statistical agencies should measure the cost of getting whatever current inputs are used to treat the diagnosis.

In the case of cataract surgery, the bundle of goods has changed substantially--notably the shift from multi-day hospitalization to outpatient surgery. By pricing the care for the cataract rather than a fixed bundle of inputs, more subtle changes in treatment could also be measured. For example, before IOLs, the cost of prescribing, fitting, and purchasing spectacles or contact lenses would be included. With

\footnotetext{
${ }^{26}$ The comparison with the published general price level is somewhat misleading because the total CPI is subject to an upward bias, estimated to be about 1 percentage point per year. See Shapiro and Wilcox (1996). Part of this bias arises because the CPI misses the decline in many levels of prices, not just in medical care. For example, when a discount store enters a market, none of the decline in the level of its prices is recorded in the CPI unless they are matched by outlets already sampled by the CPI.
} 
IOLs, those charges would disappear, but charges for prescribing the IOL in advance of surgery and for the IOL itself would appear. Additionally, changes in the cost of how anaesthesia is administered as operative techniques have improved could be taken into account. Finally, a unit value approach would capture fee reductions and discounts specific to the particular procedure. For example, Medicare has substantially reduced reimbursement for cataract relative to other procedures, so the BLS component index will overstate the increase in physician cost as it applied to cataract.

Cataract is perhaps a more circumscribed or easier to define diagnosis than average. Nonetheless, this approach should be feasible for other diseases. For example, for kidney stones, what should be priced is the removal of the stones, whether by surgery or lithotripsy. More open-ended treatments, such as for management of chronic hypertension, might be harder to define. Nonetheless, experts could specify treatment regimes for such diseases, that could be changed as medical practice warrants.

At least for the period where Medicare data are available, it might be possible to construct a unit value series for cataract along the lines Cutler, et al. (1998) have done for heart attacks. We have not attempted to do so, however, for this paper. ${ }^{27}$

\subsubsection{BLS Procedures}

As discussed above, the BLS pricing of medical care has been based on the pricing of inputs. Recently, the BLS has made substantial progress away from pricing inputs toward the pricing of medical treatments. ${ }^{28}$ In much of the PPI for hospital services and, to a more limited extent in the CPI, the BLS prices hospital bills. Its procedure is to sample a non-Medicare bill for a pre-determined procedure. It then returns to the hospital on a monthly basis and reprices the items that appear on the bill. By pricing a bill

\footnotetext{
${ }^{27}$ Using Medicare records to study cataract is complicated, however, by the change from hospital (covered by part A) to outpatient (covered by part B).

${ }^{28}$ For a description of health care in the PPI, see Dennis Fixler and Mitchell Ginsburg (this volume); for the CPI, see Ina Kay Ford and Daniel Ginsburg (this volume).
} 
over time, the BLS has made a major step toward pricing the treatment of the disease per se rather than a fixed bundle of inputs. It does have an important limitation in that it does not automatically capture changes in the treatment for a diagnosis. For example, a bill for a cataract extraction might have an entry for the suture. Increasingly, cataracts operations are sutureless. The BLS procedure would continue to price the suture even if the item were dropped from the bill absent an adjustment. ${ }^{29}$ Such changes in treatment of a fixed are very common. They can either increase or decrease cost.

The BLS does recognize the issue of changing treatment. There are procedures for making adjustments in the bills to be priced to take them into account. Yet, as of this writing, such adjustments have not been made. Moreover, making such adjustments requires substantial medical knowledge. For substantial changes in treatment, it would probably be necessary to have the linkage of bills to be priced monitored by medical experts (see Shapiro, Shapiro, and Wilcox (1999) for such a suggestion).

An alternative procedure could address the problem of changing techniques of treatment. Instead of sampling a fixed bill and attempting to reprice it, the BLS could price hospital admissions or physician care for a fixed diagnosis. That is, it should price a bill for a routine cataract extraction, a heart attack without other medical problems, the setting of a broken bone, the removal of kidney stones or gall bladder, etc. If the treatment modalities change over time, at increased or decreased cost, those changes should be reflected in the unit value. Presumably, such a procedure would require some oversight by medical experts, for example, to alert the BLS to the shift from spectacles to IOLs. This oversight need not be month-tomonth, but it would have to be much more frequent than the 10-year periods that typically elapse between benchmark revisions.

\subsection{Durability and Quality-Adjustment}

\footnotetext{
${ }^{29}$ Saving the cost of the suture is not the main reason for moving to sutureless surgery. Sutureless surgery can result in superior post-operative results and increased rates of recover.
} 
Medical procedures such as cataract extraction provide a service flow often extending far beyond the period the treatment is received. The failure to appropriately account for durability arises for many goods, not just health care. Indeed, only for housing is there a systematic attempt in the CPI and the National Accounts to account for the service flow rather than the purchase of the durable.

Health care could be handled analogously to housing by imputing a service flow to the stock of health procedures. In the case of cataract extraction, this procedure would keep track of all those alive who had the operation. It would impute a flow value of having had the operation to this stock. While conceptually feasible, this approach would require substantial data and the ability to impute value. Unlike housing, where there is a rental market that can be used to impute value ${ }^{30}$ the value of medical procedures would have to be imputed indirectly.

Even if the rental-equivalence approach were not taken, the durability of medical procedure needs to be taken into account when considering its purchase price. As discussed in Section 3, the capitalized benefit of medical procedures includes the avoidance of worsening symptoms as the disease progresses in the future. To appropriately quality-adjust the purchase of medical procedure, this future value must be taken into account. Hence, measuring the quality-adjusted purchase price does not avoid the problems of imputing the value of the stock of health care procedures that appears in the rental-equivalence approach. It merely changes what stock gets valued. For the rental-equivalence approach, the stock of procedures across individuals at a point in time must be valued. For the purchase-price approach, the discounted value of the procedure for the cross-section of individuals currently receiving the procedure must be valued.

\subsection{Heterogeneity of Valuations}

The reduced cost and increased benefit of cataract surgery has substantially increased the demand for the procedure. As Section 3 makes clear, the valuations of different patients getting the surgery are

\footnotetext{
${ }^{30}$ The service flow of cars could similarly be imputed using lease payments.
} 
quite different. When the underlying disease progresses at different rates, patients who look identical at the time of surgery might have very different lifetime valuations. Hence, even a careful study of the improvement in visual status arising directly from the operation will not capture all of the differences in valuation. As the cost falls and the aggregate demand for the procedure increases, at the time of surgery, a patient with progressive disease will move from being pooled with those with severe disease to being pooled with those who have mild disease. Absent a dynamic model of the underlying disease, the benefits of the procedure might be substantially understated.

\section{6. $\quad$ Conclusions}

In this paper, we presented evidence about the costs and value of cataract surgery. We find that the monetary cost of cataract--in contrast to standard price indexes for health care--has not been increasing faster than the general price level. Moreover, we discuss how improvements in the technique for cataract extraction and how the transition for spectacles or contact lenses to intraocular lenses have improved the quality of the outcomes. As techniques have changed, patients have much faster ambulation, face lower rates of complications, and have better post-operative visual outcomes. These reductions in the total cost of the procedure from the point of view of the patient have led to substantial increases in the rate of cataract extraction. Patients with less severe disease are having the operation, and patients are getting the operation earlier in the course of the disease. While there is not a sufficient knowledge base to quantify the gains in lifetime utility arising from the greater frequency of cataract operations, it is clear that a qualityadjustment would--on top of the essentially flat relative price of cataract extraction in monetary terms--lead to a substantial decline in the real price of cataract extraction.

The analysis of cataract extraction leads us to make some specific recommendations that have broader applicability to measuring the price of health care. First, the cost of procedures be measured in terms of unit values for treating particular diagnoses. Second, the durability of the benefits accruing from 
medical procedures needs to be taken into account in measuring their value. Third, changes in the cost of medical procedures changes the mix of patients getting the treatment, both in terms of severity of the disease and the timing of the procedure within the course of the disease. Consequently, patients with progressive disease will be treated when their symptoms are severe when costs are high and when their symptoms are less severe when costs are lower. How the population of patients receiving treatment changes endogenously in response to changes in cost needs to be taken into account appropriately.

The lessons from cataract should have wide applicability. In particular, for many diseases, treatment has moved earlier in the course of the disease as the treatment regime has improved. Potentially important examples include increasing rates of heart bypass operations, especially for pain and function, more frequent joint replacements, and cochlear implants for less severe nerve deafness. While the monetary cost of these procedures might not have the favorable dynamics of those for cataracts, they share with cataracts that much of their benefits occur as patients, by getting the procedures earlier, avoid a substantial period of worsening symptoms and declining quality of life. Therefore, the lessons of cataract surgery should have wide application to measuring health care prices. 
References

Anderson, Gerald, Charlyn Black, Elaine Dunn, Jordi Alonso, Jens Christian Nørregard, Tavs FolmerAnderson, and Peter Bernth-Petersen. Willingness to Pay to Shorten Waiting Time for Cataract Surgery. Health Affairs 16 (1997) 181-190.

Baratz, Keith H., Darryl T. Gray, David O. Hodge, Linda C. Butterfield, and Duane M. Ilstrup. Cataract Extraction Rates in Olmsted County, 1980 Through 1994. Archives of Ophthalmology 115 (1997) 14411446.

Bass, Eric B., Stacey Wills, Ingrid U. Scott, Jonathan C. Javitt, James M. Tielsch, Olivier D. Schein, and Earl P. Steinberg. Preference Values for Visual States in Patients Planning to Undergo Cataract Surgery. Medical Decision Making 17 (1997) 324-330.

Bernth-Petersen, Peter. A Change in Indications for Cataract Surgery? A 10 Year Comparative Epidemiologic Study. Acta Ophthalmologica 59 (1981) 206-210.

Braendstrup, P. Senile Cataract: Account of Cataract Extractions Performed in an Urbanized Population During the Third Quarter of the Present Century. Acta Ophthalmologica 55 (1977) 337-347.

Chernew, M., A.M. Fendrick, and R.A. Hirth. Managed Care and Medical Technology. Health Affairs 16 (1997) 196-206.

Cutler, David, Mark McClellan, Joseph Newhouse, and Dahlia Remler. Pricing Heart Attack Treatments. This Conference (1998).

Diewert, W.E. Index Numbers. The New Palgrave. London: MacMillan Press, 1987.

Drummond, Michael F. Economic Aspects of Cataract. Ophthalmology 95 (1988) 1147-1153.

Drummond, Michael F., ed. Measuring the Quality of Life of People with Visual Impairment. NIH Publication No. 90-3078 (1990).

Ferguson, B.A., M.J. Buxton, and M.F. Drummond. Measuring and Valuing Health States Relating to Visual Impairment: A Review of the Literature, Concepts, and Methods. Appendix A of Drummond (1990).

Fixler, Dennis and Ginsburg, Mitchell. Health Care Output and Prices in the Producer Price Index, in Berndt and Cutler, eds., Medical Care Output and Productivity. NBER-CRIW Conference Volume, 1998 (in process).

Ford, Ina Kay and Ginsburg, Daniel B. Medical Care in the CPI, in Berndt and Cutler, eds., Medical Care Output and Productivity. NBER-CRIW Conference Volume, 1998 (in process).

Miglior, Stefano, Alfredo Nicolosi, Paolo E. Mariaghi, Luca Migliavacca, Cristina Balestreri, Pasquale Troiona, Mario Miglior, and Nicola Orzalesi. Trends in Cataract Surgery in Milan (Italy) from 1956 to 1987. Acta Ophthalmologica 70 (1982) 395-401. 
Moorman, Consuela, Alfred Sommer, Walter Stark, Cheryl Enger, John Payne, and A. Edward Maumenee. Changing Indications for Cataract Surgery: 1974 to 1988. Ophthalmic Surgery 21 (1990) 761- 766.

Nadler, Daniel J. and Bernard Schwartz. Cataract Surgery in the United States, 1968-1976, A Descriptive Epidemiologic Study. Ophthalmology 87 (1980) 10-17.

Nørregaard, Jen Christian, Peter Bernth-Petersen, and Tavs Folmer Andersen. Changing Threshold for Cataract Surgery in Denmark between 1980 to 1992. Acta Ophthalmologica Scandinavica 74 (1996) 604608.

Pollak, Robert A. The Theory of the Cost-of-Living Index. New York: Oxford University Press, 1989.

Shapiro, Irving, Matthew D. Shapiro, and David W. Wilcox. Quality Improvements in Health Care: A Framework for Price and Output Measurement. American Economic Review Papers and Proceedings (May 1999).

Shapiro, Matthew D. and David W. Wilcox. Mismeasurement of the Consumer Price Index: An Evaluation. NBER Macroeconomics Annual 11 (1996) 93-142.

Steinberg, Earl P., James M. Tielsch, Oliver D. Schein, Jonathan C. Javitt, Phoebe Sharkey, Sandra D. Cassard, Marcia W Legro, Marie Diener-West, Eric C. Bass, Anne M. Damiano, Donald M. Steinwachs, and Alfred Sommer. The VF-14: An Index of Functional Impairment in Patients With Cataract. Archives of Ophthalmology 112 (1994) 630-638.

Torrance, George W., Michael W. Boyle, and Sargent H. Horwood. Application of Multi-Attribute Utility Theory to Measure Social Preferences for Health States. Operations Research 30 (1982) 1043-1069. 
Table 1

Typical Cataract Treatment: A Brief Chronology

\begin{tabular}{|c|c|c|c|}
\hline Year & Procedure & $\begin{array}{l}\text { Typical } \\
\text { Length of } \\
\text { Hospital } \\
\text { Stay } \\
\text { (Nights) } \\
\end{array}$ & Comments \\
\hline 1947 & $\begin{array}{l}\text { Extracapsular } \\
\text { extraction }\end{array}$ & 7 & $\begin{array}{l}\text { Cataract removed by } \\
\text { irrigation }\end{array}$ \\
\hline 1952 & $\begin{array}{l}\text { Intracapsular } \\
\text { extraction }\end{array}$ & 7 & $\begin{array}{l}\text { Cataract removed by freezing } \\
\text { and/or suction }\end{array}$ \\
\hline 1969 & $\begin{array}{l}\text { Intracapsular } \\
\text { extraction }\end{array}$ & 3 & $\begin{array}{l}\text { Improved methods of } \\
\text { extraction and suturing; } \\
\text { routine use of operating } \\
\text { microscope }\end{array}$ \\
\hline 1972 & $\begin{array}{l}\text { Controlled } \\
\text { Extracapsular } \\
\text { extraction }\end{array}$ & 1 & $\begin{array}{l}\text { Modern extracapsular } \\
\text { extraction pioneered with } \\
\text { phacoemulsification; typical } \\
\text { extraction remains } \\
\text { intracapsular }\end{array}$ \\
\hline 1979 & $\begin{array}{l}\text { Intracapsular and } \\
\text { extracapsular }\end{array}$ & $\begin{array}{l}1 \text { or } \\
\text { outpatient }\end{array}$ & IOLs in increasing use \\
\hline 1985 & $\begin{array}{l}\text { Extracapsular } \\
\text { extraction with } \\
\text { (IOL) }\end{array}$ & Outpatient & $\begin{array}{l}\text { Techniques to lessen } \\
\text { complications; improved } \\
\text { incisions and placement of } \\
\text { IOL }\end{array}$ \\
\hline 1990 & $\begin{array}{l}\text { Extracapsular } \\
\text { extraction with } \\
(\text { IOL) }\end{array}$ & Outpatient & $\begin{array}{l}\text { Phacoemulsification now } \\
\text { common for extraction; IOLs } \\
\text { developed for small incision }\end{array}$ \\
\hline 1995 & $\begin{array}{l}\text { Extracapsular } \\
\text { extraction with } \\
\text { (IOL) }\end{array}$ & Outpatient & New incisions \\
\hline 1998 & $\begin{array}{l}\text { Extracapsular } \\
\text { extraction with } \\
\text { (IOL) }\end{array}$ & Outpatient & $\begin{array}{l}\text { Quicker operations allow } \\
\text { reduced anaesthesia; } \\
\text { Anaesthesia infused; } \\
\text { Multifocal IOL becoming more } \\
\text { common }\end{array}$ \\
\hline
\end{tabular}


Table 2

Post-Operative Optical Correction

\begin{tabular}{lll}
\hline Optical Correction & Ease of Use & Magnification \\
\hline Spectacles & Fair to Good & Yes \\
Contact Lens & Fair to poor & Minimal \\
Intraocular Lens & Excellent & No \\
\hline
\end{tabular}

Note: Magnification of corrected vision in operated eye impairs use of unoperated eye. 
Table 3

Indications for Cataract Surgery:

Visual Acuity in Better Eye

\begin{tabular}{|c|c|c|c|c|c|c|}
\hline \multirow[t]{2}{*}{ Years } & \multirow[t]{2}{*}{ Location } & \multicolumn{3}{|c|}{$\begin{array}{c}\text { Percent of Patients } \\
\text { by Visual Acuity }\end{array}$} & \multirow[t]{2}{*}{ Operated Eye } & \multirow[t]{2}{*}{ Source } \\
\hline & & $>20 / 60$ & $\begin{array}{l}20 / 60- \\
20 / 100 \\
\end{array}$ & $\leq 20 / 200^{*}$ & & \\
\hline $1947-50$ & \multirow[t]{2}{*}{ Copenhagen } & 15 & 55 & 30 & \multirow[t]{2}{*}{$\begin{array}{l}\text { Bilateral; } \\
\text { First Eye }\end{array}$} & \multirow[t]{2}{*}{ A } \\
\hline $1969-70$ & & 15 & 68 & 17 & & \\
\hline 1970 & \multirow[t]{2}{*}{ Aarhus } & 28 & 64 & 9 & $\begin{array}{l}\text { Bilateral; } \\
\text { First eye }\end{array}$ & B \\
\hline 1980 & & 33 & 59 & 8 & & \\
\hline 1980 & \multirow[t]{2}{*}{ Aarhus } & 27 & 62 & $11^{*}$ & \multirow[t]{2}{*}{ Monocular } & \multirow[t]{2}{*}{$\mathrm{C}$} \\
\hline 1992 & & 56 & 42 & 1 * & & \\
\hline 1974 & \multirow[t]{3}{*}{ Baltimore; Hospital Practice } & 48 & 30 & 16 & \multirow[t]{3}{*}{ First Eye } & \multirow[t]{3}{*}{$\mathrm{D}$} \\
\hline 1982 & & 67 & 20 & 14 & & \\
\hline 1988 & & 68 & 21 & 10 & & \\
\hline 1974 & \multirow[t]{3}{*}{ Baltimore; Community Practice } & 54 & 33 & 12 & \multirow[t]{3}{*}{ First Eye } & \multirow[t]{3}{*}{$\mathrm{D}$} \\
\hline 1982 & & 46 & 37 & 17 & & \\
\hline 1988 & & 60 & 33 & 6 & & \\
\hline 1974 & \multirow[t]{3}{*}{ Baltimore; Hospital Practice } & 59 & 14 & 27 & \multirow[t]{3}{*}{ Second Eye } & \multirow[t]{3}{*}{$\mathrm{D}$} \\
\hline 1982 & & 80 & 9 & 11 & & \\
\hline 1988 & & 84 & 5 & 11 & & \\
\hline 1974 & \multirow[t]{3}{*}{ Baltimore; Community Practice } & 83 & 10 & 7 & \multirow[t]{3}{*}{ Second Eye } & \multirow[t]{3}{*}{$\mathrm{D}$} \\
\hline 1982 & & 92 & 3 & 5 & & \\
\hline 1988 & & 93 & 7 & 0 & & \\
\hline
\end{tabular}

See below for sources and notes. 
Table 4

Indications for Cataract Surgery:

Visual Acuity in Operated Eye

\begin{tabular}{|c|c|c|c|c|c|c|}
\hline \multirow[t]{2}{*}{ Year } & \multirow[t]{2}{*}{ Location } & \multicolumn{3}{|c|}{$\begin{array}{c}\text { Percent of Patients } \\
\text { by Visual Acuity }\end{array}$} & \multirow[t]{2}{*}{ Operated Eye } & \multirow[t]{2}{*}{ Source } \\
\hline & & $>20 / 60$ & $\begin{array}{l}20 / 60- \\
20 / 100 \\
\end{array}$ & $\leq 20 / 200^{*}$ & & \\
\hline 1980 & Aarhus & 0 & 31 & $69^{*}$ & Monocular & $\mathrm{C}$ \\
\hline 1992 & & 13 & 59 & $28^{*}$ & & \\
\hline 1974 & Baltimore; Hospital Practice & 12 & 21 & 67 & $\begin{array}{l}\text { First or } \\
\text { second }\end{array}$ & $\mathrm{D}$ \\
\hline 1982 & & 19 & 30 & 51 & & \\
\hline 1988 & & 24 & 36 & 40 & & \\
\hline 1974 & Baltimore; Community Practice & 11 & 34 & 55 & $\begin{array}{l}\text { First or } \\
\text { second }\end{array}$ & $\mathrm{D}$ \\
\hline 1982 & & 5 & 30 & 65 & & \\
\hline 1988 & & 8 & 70 & 22 & & \\
\hline
\end{tabular}

See below for notes and sources. 
Notes and sources for Tables 3 and 4 .

Sources:

A Braendstrup (1977). Patients admitted for operation of first cataract of bilateral cataract at the Municipal Hospital of Copenhagen. Patients at least 40 years old.

B Bernth-Petersen (1981). Patients at Aarhus Kommunehospital. Monocular. Bilateral also reported (not tabulated). Patients with glaucoma excluded.

C Nørregaard, Pernth-Petersen, and Andersen (1996). Patients at Aarhus University Hospital (from B) and from national sample of public health service hospitals. First eyes only. Patients with glaucoma and dementia excluded.

D Moorman, et al. (1990). Randomly selected cataract operations from hospital- and community-based physicians. Mix of first and second eyes.

${ }^{*}$ For source B, the 20/100 acuity is excluded from the second column and included in the third.

For the Danish studies, visual acuities are converted from metric units. 


\section{Table 5}

Inputs for Cataract Surgery

Units: 1 = One Night in Hospital

\begin{tabular}{lccc|c|c}
\hline & $\begin{array}{c}\text { Hospital } \\
\text { Nights }\end{array}$ & $\begin{array}{c}\text { Hospital } \\
\text { Operating } \\
\text { Room }\end{array}$ & $\begin{array}{c}\text { Total } \\
\text { Operation } \\
\text { Room }\end{array}$ & $\begin{array}{c}\text { Hospital/ } \\
\text { Outpatien } \\
\text { t }\end{array}$ & Surgeon \\
\hline 1969 & 3 & 4 & 0 & 7 & 1 \\
1972 & 1 & 4 & 0 & 5 & 1 \\
$1979^{a}$ & $5 \times 1$ & $.5 \times 4$ & $.5 \times 1.5$ & 3.25 & 1 \\
1985 & 0 & 0 & 1.5 & 1.5 & 0.8 \\
1994 & 0 & 0 & 1.5 & 1.5 & 0.7 \\
1998 & 0 & 0 & 1.3 & 1.3 & 0.5 \\
\hline
\end{tabular}

an 1979, one-half inpatient and one-half outpatient. 
Table 6

Expenditure Weights for Cataract Surgery

\begin{tabular}{lcc}
\hline & Hospital/Outpatient & Surgeon \\
\hline 1969 & 0.808 & 0.192 \\
1972 & 0.776 & 0.224 \\
1979 & 0.736 & 0.264 \\
1985 & 0.656 & 0.344 \\
1994 & 0.725 & 0.275 \\
\hline
\end{tabular}


Table 7

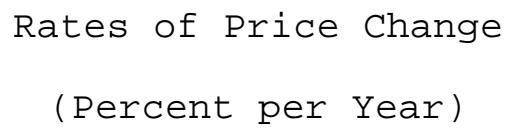

\begin{tabular}{|c|c|c|c|c|c|}
\hline & Cataract & Surgery & & $\mathrm{CPI}$ & \\
\hline & $\begin{array}{c}\text { Prototypical } \\
\text { Index }\end{array}$ & $\begin{array}{c}\text { Hypothetical } \\
\text { CPI }\end{array}$ & $\begin{array}{c}\text { Hospital } \\
\text { Room }\end{array}$ & $\begin{array}{c}\text { Physician } \\
\text { Services }\end{array}$ & Total \\
\hline \multicolumn{6}{|c|}{ Nominal } \\
\hline $\begin{array}{l}1969- \\
1972\end{array}$ & 0.2 & 9.6 & 10.5 & 5.5 & 4.5 \\
\hline $\begin{array}{l}1972- \\
1979\end{array}$ & 5.5 & 10.8 & 11.4 & 8.0 & 8.2 \\
\hline $\begin{array}{l}1979- \\
1985\end{array}$ & -0.1 & 10.9 & 11.5 & 8.4 & 6.8 \\
\hline $\begin{array}{l}1985- \\
1994\end{array}$ & 7.1 & 7.9 & 8.3 & 6.0 & 3.6 \\
\hline $\begin{array}{l}1969- \\
1994 \\
\end{array}$ & 4.1 & 9.6 & 10.2 & 7.1 & 5.7 \\
\hline \multicolumn{6}{|c|}{ Relative to Total CPI } \\
\hline $\begin{array}{l}1969- \\
1972\end{array}$ & -4.3 & 5.2 & 6.1 & 1.1 & \\
\hline $\begin{array}{l}1972- \\
1979\end{array}$ & -2.7 & 2.6 & 3.2 & -0.2 & \\
\hline $\begin{array}{l}1979- \\
1985\end{array}$ & -6.9 & 4.1 & 4.7 & 1.6 & \\
\hline $\begin{array}{l}1985- \\
1994\end{array}$ & 3.5 & 4.3 & 4.7 & 2.4 & \\
\hline $\begin{array}{l}1969- \\
1994\end{array}$ & -1.7 & 3.9 & 4.4 & 1.3 & \\
\hline
\end{tabular}


Figure 1

Cataract Extraction Rates in Olmsted County, Minnesota

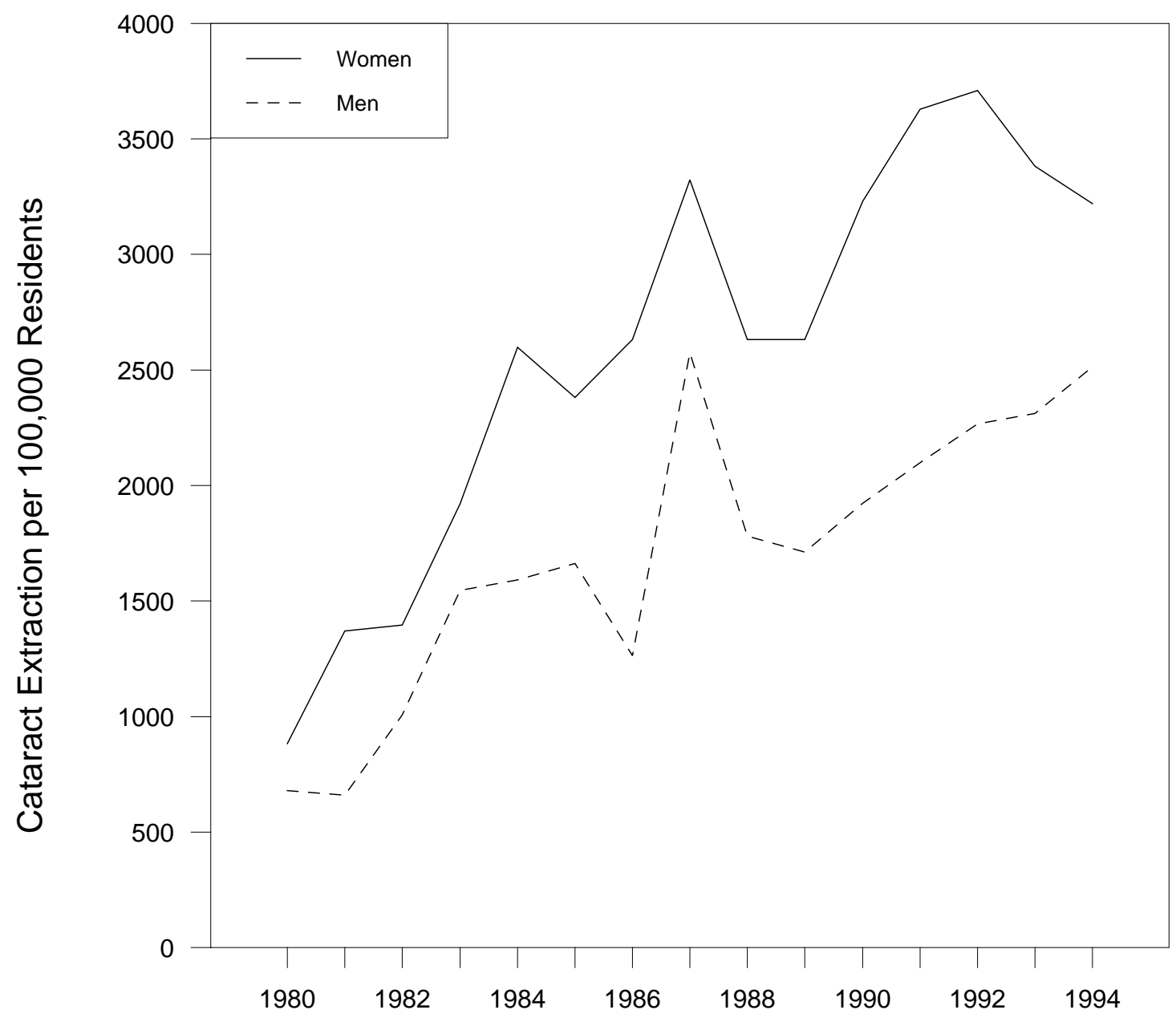

Source: Baratz, et al. (1997). The rates are for individuals aged at least 65 years. 
Figure 2. Timing of Surgery Under Changing Treatment Regimes for Patients with Different Courses of Disease (Benefits Shaded)

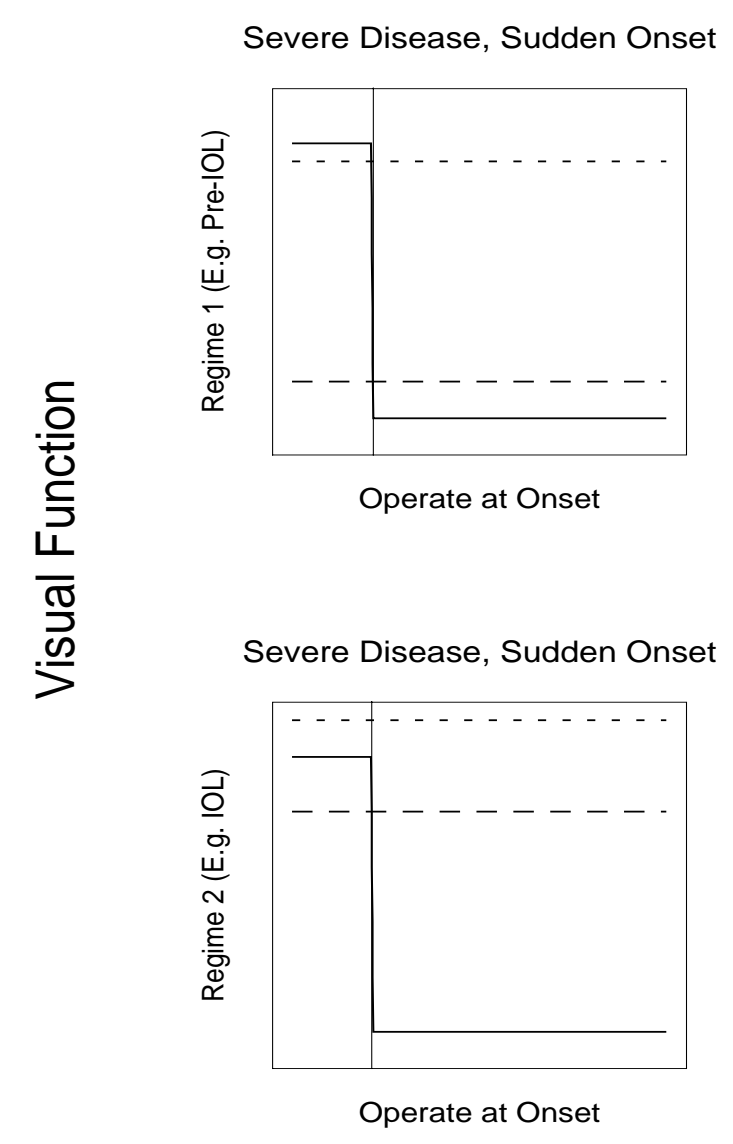

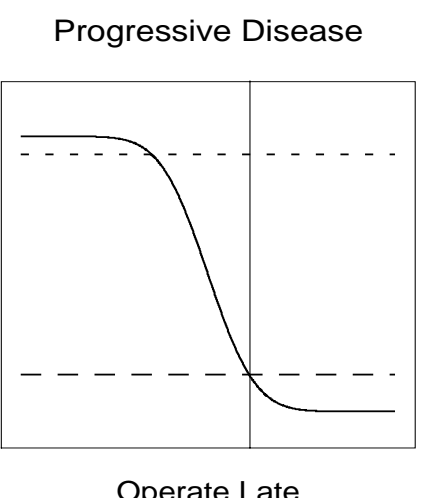

Operate Late

Progressive Disease

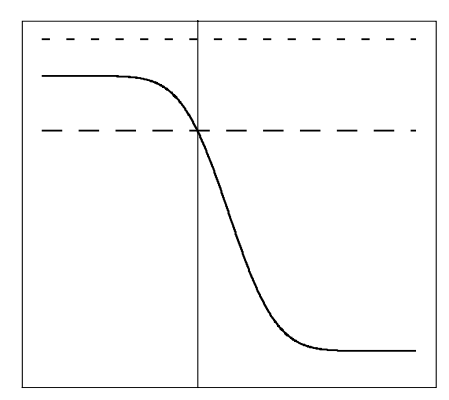

Operate Earlier
Mild Disease, Sudden Onset

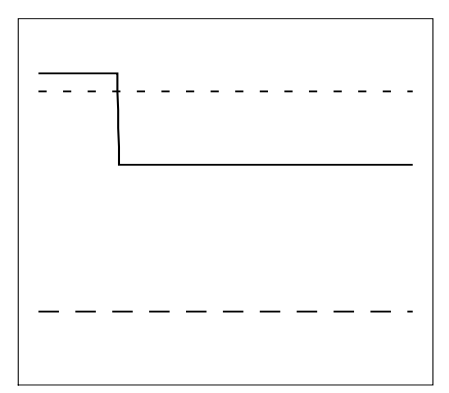

Do Not Operate

Mild Disease, Sudden Onset

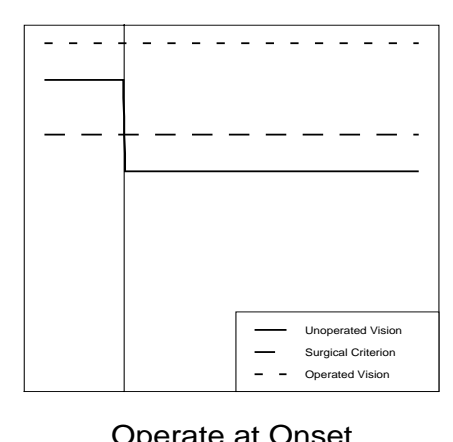

Age 
Figure 3

\section{Prototypical Cost Index versus Hypothetical CPI for Cataract Surgery}

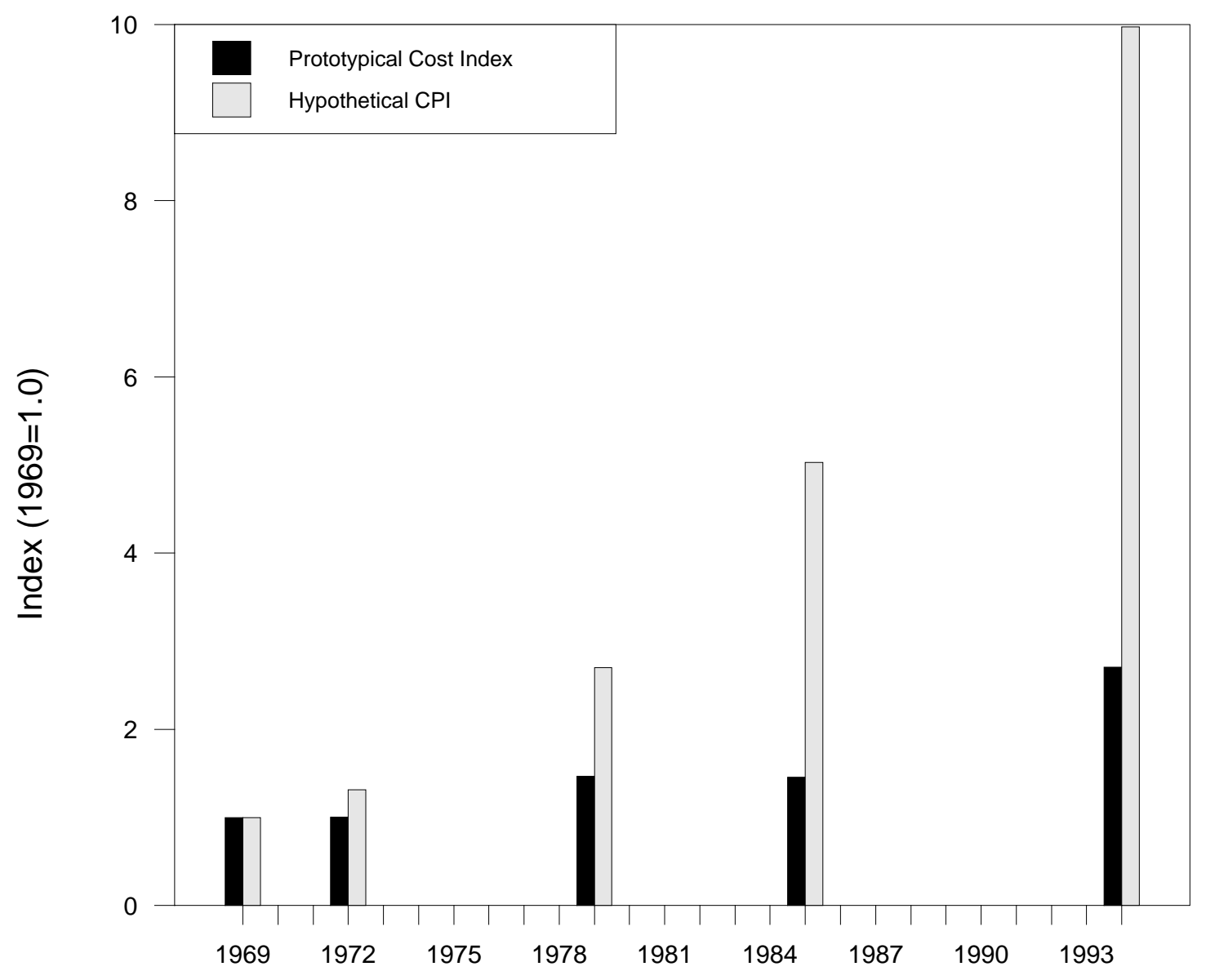

Source: Authors' calculations. See text for details. 